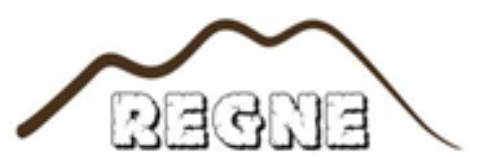

\title{
Ferramentas Tecnológicas como Recurso Didático: uma experiência de desenvolvimento da Cartografia Escolar com apoio em Geotecnologias na formação docente
}

\author{
technological tools as a didactic resource: a development experience of School \\ Cartography with support in Geotechnologies in teacher training \\ MEDEIROS $^{1}$, T. D. S.; VASCONCELOS ${ }^{2}$, P. R. M.; MENEZES ${ }^{3}$, E. H. S.; \\ SILVA ${ }^{4}$, L. C. M. \\ thiagodsmedeiros@outlook.com;
}

\section{RESUMO}

\begin{abstract}
Geography classes have undergone changes in their didactics due to the emerging of new teaching tools for them. They can be used by teachers as long as they are skilled enough to do so. Keeping this in mind, the present work discusses an experiment report of an extension project, developed at Centro de Ensino Superior do Seridó, in Universidade Federal do Rio Grande do Norte, during which a mini-course was developed for future teachers, using the free software Quantum Gis. Therefore, teaching material was produced with basic information about its operation, with applications related to the development of Geography classes. And, from the data obtained and analyzed, there is some interest, on the part of future teachers, in learning how to use geotechnologies to be introduced in Geography Teaching.
\end{abstract}

As aulas de Geografia vêm sofrendo mudanças em sua didática por surgirem, cada vez mais, novas ferramentas para o seu ensino. Elas podem ser administradas pelos docentes desde que os mesmos tenham habilidades para isso. Pensando nisso, o presente trabalho trata de um relato de experiência a partir de um projeto de extensão, desenvolvido no Centro de Ensino Superior do Seridó da Universidade Federal do Rio Grande do Norte, onde desenvolveu-se um minicurso para futuros professores, a partir do uso do programa gratuito Quantum GIS. Desse modo, foi produzido material didático contendo informações básicas do referido programa, voltadas à sua operação, aplicadas ao desenvolvimento de aulas de Geografia. A partir dos dados obtidos e analisados, percebeu-se um interesse por parte dos formandos em aprender o manuseio das geotecnologias para introduzi-las no Ensino de Geografia.

Palavras-chaves: Ensino de Geografia,

Keywords: Geography Teaching, Geotechnologies, Teaching Resources.

${ }^{I}$ Thiago Douglas Silva de Medeiros, Departamento de Geografia, Universidade Federal do Rio Grande do Norte, Caicó RN, Brasil.

${ }^{2}$ Paulo Roberto Medeiros Vasconcelos, Departamento de Geografia, Universidade Federal do Rio Grande do Norte, CaicóRN, Brasil.

${ }^{3}$ Edson Helder Silva de Menezes, Departamento de Geografia, Universidade Federal do Rio Grande do Norte, Caicó-RN, Brasil.

${ }^{4}$ Luana Carla Mariz da Silva, Departamento de Geografia, Universidade Federal do Rio Grande do Norte, Caicó-RN, Brasil. 


\section{INTRODUÇÃO}

O ensino de Geografia, assim como outras áreas de ensino, passou e passa por diversas mudanças, no intuito de aperfeiçoar suas práticas pedagógicas. Melhorar no sentido de ensinar, de tal forma que o processo de ensino-aprendizagem seja mais eficaz. A este respeito, Cavalcanti afirma que:

O movimento de renovação do ensino de Geografia, no Brasil, nos últimos 20 anos, tem sido marcado pela abertura de espaços de debates científicos (...) para a discussão e a divulgação de novas propostas, pela produção de trabalhos dedicados a esse tema e, também, pela produção de livros didáticos que buscam operacionalizar tais propostas. (CAVALCANTI, 1998, p. 20)

Hoje, as novas tecnologias constituem aparato de grande valia na vivência dos estudantes, uma vez que, com o crescente desenvolvimento da informática, há muitas ferramentas as quais são utilizadas por eles em seu dia-a-dia, a exemplo de Sistemas de Posicionamento Global (tais como aqueles usados em celulares e veículos), além de aplicativos de computação de operação mais viável (Google Earth, Sistemas de Informações Geográficos - SIG voltados ao ensino), os quais podem ser utilizados como importante suporte para o desenvolvimento das aulas de Geografia. No entanto, estes devem ser trabalhados com auxílio e orientação do professor de Geografia, para que esta inserção venha a contribuir com o desenvolvimento cognitivo dos alunos, e, assim, transformá-las em recursos didáticos; por exemplo: desenvolvendo atividades de orientação no espaço, interpretação das paisagens e etc. Todas estas são habilidades possíveis de serem desenvolvidas a partir do uso de mapas digitais, com o auxílio de SIG.

Outro apontamento importante é que, muitos dos aplicativos de celulares, por exemplo, chegam ao ambiente escolar, mesmo sem seu consentimento. Logo, se torna cada vez mais necessário o saber administrá-las, de forma a refletir sobre possibilidades de aplicação das mesmas, não só nas aulas de Geografia, mas em diversas outras disciplinas. Segundo Aguiar (2013, p.54) "o uso de geotecnologias e os seus mais diversos métodos de análise permitem uma vasta aplicação nos ramos das ciências, sendo uma ferramenta muito útil para ensinar Geografia".

Todo professor sabe do valor indiscutível que o computador e a internet têm do ponto de vista do desenvolvimento de pesquisa acerca de determinado tema ou assunto. A relativa facilidade de acesso permite obter uma série de informações sobre determinado tópico, facilitando enormemente uma pesquisa que, em outros tempos, demoraria muito para ser realizada. (PONTUSCHKA; PAGANELLI; CACETE, 2009, p. 263) 
Sabendo disso, será relatado aqui, a proposta de capacitação aos docentes e discentes do curso de graduação em Geografia, do Centro de Ensino Superior do Seridó, da Universidade Federal do Rio Grande do Norte (CERES/UFRN), assim como para professores da rede pública e privada de ensino do município de Caicó ( $\mathrm{RN}$ ), muitos deles, alunos de mestrado do Programa de Pós-Graduação em Geografia (GEOPROF) do mesmo centro, para manuseio básico do programa Quantum GIS, que é um SIG (Sistema de Informação Geográfica) livre, e que possui ferramentas com grande potencial para serem utilizadas como recursos didáticos nas aulas de Geografia do ensino básico.

Tal curso foi realizado, ao perceber-se que um dos maiores impeditivos para a utilização dessas ferramentas em sala de aula reside no fato que muitos docentes ainda estão presos ao livro didático, privando-se de recorrer a qualquer outro recurso didático, por resistência ou até mesmo por falta de atualização, tornando as aulas de geografia enfadonhas e, portanto, pouco atrativas. Na visão de Pontuschka, Paganelli e Cacete (2009, p.343): “o livro didático deveria configurar-se de modo que o professor pudesse tê-lo como instrumento auxiliar de sua reflexão geográfica com seus alunos, mas existem fatores limitantes para tal”.

Assim, a inserção do Geoprocessamento nas aulas de Geografia, constitui importante forma de dinamização dos métodos de ensino, ajudando na compreensão de conteúdos geográficos, no entendimento da dinâmica das paisagens, dentre outras possibilidades. É o que espera os Parâmetros Curriculares Nacionais $(\mathrm{PCN})$, quando afirma que há várias formas de ensinar geografia, para o desenvolvimento de competências e habilidades nos alunos. Em um de seus trechos, o PCN do ensino fundamental, por exemplo, expõe que:

O estudo da linguagem cartográfica, por sua vez, tem cada vez mais reafirmando sua importância, desde o início da escolaridade. Contribui não apenas para que os alunos venham a compreender e utilizar uma ferramenta básica da Geografia, os mapas, como também para desenvolver capacidades relativas à representação do espaço. (BRASIL, 2001, p. 118)

Sabe-se, portanto, que os PCN, trabalham com a certeza de que estas competências devem ser trabalhadas como um meio de viabilizar de forma eficaz, a compreensão das categorias da ciência geográfica, de modo que venha a contribuir significativamente para a capacidade de leitura, compreensão e transformação da realidade social. Além disso, o mesmo parâmetro, também orienta a desenvolver nos alunos, a clareza do uso do domínio de linguagens próprias da análise geográfica para identificar fenômenos dessa natureza presentes 
nos espaços vividos, a partir, por exemplo, da utilização de mapas e gráficos, desenvolvendo a habilidade de reconhecer variadas formas de representação do espaço: cartográfica, tratamentos gráficos, matemáticos e estatísticos.

Sendo assim, o objetivo do presente trabalho consistiu em capacitar os docentes e discentes do espaço universitário, assim como professores da rede pública e privada de ensino básico, no uso de um SIG livre para o desenvolvimento de aulas de Geografia, o qual como uma ferramenta de acesso gratuito, possa ser utilizado em diversas realidades do ensino.

\section{METODOLOGIA}

O desenvolvimento do referido trabalho se iniciou com um período de instruções, com o objetivo de ensinar outros graduandos, professores de nível superior e de nível básico, a trabalhar com as ferramentas do SIG Quantum GIS, com o objetivo de que os mesmos possam a vir utilizá-lo como recurso didático em suas aulas. No caso dos graduandos, como futuros professores.

Antes disso, primeiramente, foi produzido um Manual básico de uso do Quantum GIS para o ensino de Geografia. Após a confecção do referido material, foram abertas inscrições para os alunos e professores do curso de graduação em Geografia da UFRN/ CERES e para a comunidade em geral (professores da rede pública e privada de ensino). A próxima etapa foi constituída pelo desenvolvimento de um minicurso com duração de dois dias, quatro horas por dia, onde foram aplicados todos os procedimentos contidos no manual mencionado. Após a conclusão do minicurso, foi aplicado um questionário com todos os participantes, visando coletar informações acerca de questões importantes, tais como:

1. Qual o seu nível de conhecimento em relação ao uso de Sistemas de Informações Geográficas?

( ) Péssimo ( ) Ruim ( ) Regular ( ) Bom ( ) Excelente

2. Na sua opinião, você julga o uso dessas tecnologias para o desenvolvimento das aulas de Geografia:

( ) Sem nenhuma importância ( ) Indiferente ( ) Bom ( ) Essencial 


\begin{tabular}{|l|}
\hline 3. Você já teve alguma espécie de contatos com Geotecnologias? \\
\hline ( ) Nenhum ( ) Algum ( ) Constantemente \\
\hline 4. Qual a importância deste curso pra você? \\
\hline ( ) Mínima ( ) Média ( ) Máxima \\
\hline 5. Você recomendaria este curso para outros colegas? \\
\hline ( ) Não ( ) Sim \\
\hline 6. Você acredita que iniciativas dessa natureza deve ocorrer com qual periodicidade? \\
\hline ( ) Anualmente ( ) Semestralmente ( )Trimestralmente \\
\hline 7. Qual a contribuição deste curso para sua formação enquanto profissional da educação? \\
\hline ( ) Sem nenhuma importância ( ) Indiferente ( ) Bom ( ) Essencial \\
\hline $\begin{array}{l}\text { 8. Numa escala de 1 a 10, quanto este curso contribuiu para seu desenvolvimento } \\
\text { profissional? }\end{array}$ \\
\hline 9. Você julgou a estrutura para o curso: \\
\hline ( ) Inadequada ( ) Razoável ( ) Adequada \\
\hline 10. Dê sugestões para os próximos cursos. \\
\hline
\end{tabular}

Fonte: Acervo do autor.

\section{RESULTADOS E DISCUSSÃO}

\subsection{Relato de experiência}

Dentre os produtos provenientes desta iniciativa pode-se citar o Manual básico de uso do Quantum GIS para o ensino de Geografia. O referido material serviu como uma valiosa orientação tanto para os participantes do projeto (alunos que ministraram o minicurso), como para os participantes do minicurso, uma vez que podem aplicar os mesmos procedimentos em suas aulas. Desse modo, o referido manual cumpre a função de um guia de orientação do docente no ensinamento dos conteúdos referentes à Geografia.

Uma das questões relevantes detectada nas inscrições para o minicurso, refere-se à participação dos professores da graduação, demonstrando a necessidade de atualização, não apenas dos professores de ensino básico, mas, também, daqueles que compõem o quadro do magistério superior. No geral, foram poucos inscritos, não havendo procura por parte dos professores do ensino básico, o que, por outro lado, não atendeu às expectativas iniciais do 
projeto, sendo compreendido como algo negativo do ponto de vista dos objetivos do minicurso. Uma possível justificativa para tal impasse, provavelmente, adveio da data de realização do minicurso, o qual foi agendado para os dias 13 e 14 do mês de dezembro de 2017. Nesse período, muitos dos alunos já estavam praticamente entrando no período de férias, havendo, apenas, 11 inscritos.

No primeiro dia do minicurso, os alunos tiveram uma introdução a respeito da aquisição do sistema adotado, aprendendo como instalá-lo, e como organizar o banco de dados. Posteriormente, foram apresentadas as ferramentas do programa, através de sua barra de menu, barra de tarefas, área de desenhos, e demais componentes que compõe a tela inicial do Quantum GIS. Em seguida, foram adquiridos os dados vetoriais georreferenciados empregados na produção dos mapas de localização de áreas escolhidas pelos alunos, com as quais os mesmos pudessem ter proximidade e interesse em levantar dados, isto para trabalhar sempre na expectativa de melhor compreensão do conteúdo ministrado.

No segundo dia foram adquiridas imagens, as quais foram processadas para utilização no mapa de localização, conferindo-o maior riqueza de informações acerca do Lugar. Posteriormente, foi realizado um exercício com os participantes, onde os mesmos produziram seus próprios mapas de localização, isto é, de maneira autônoma, utilizando os conceitos e comandos anteriormente transmitidos.

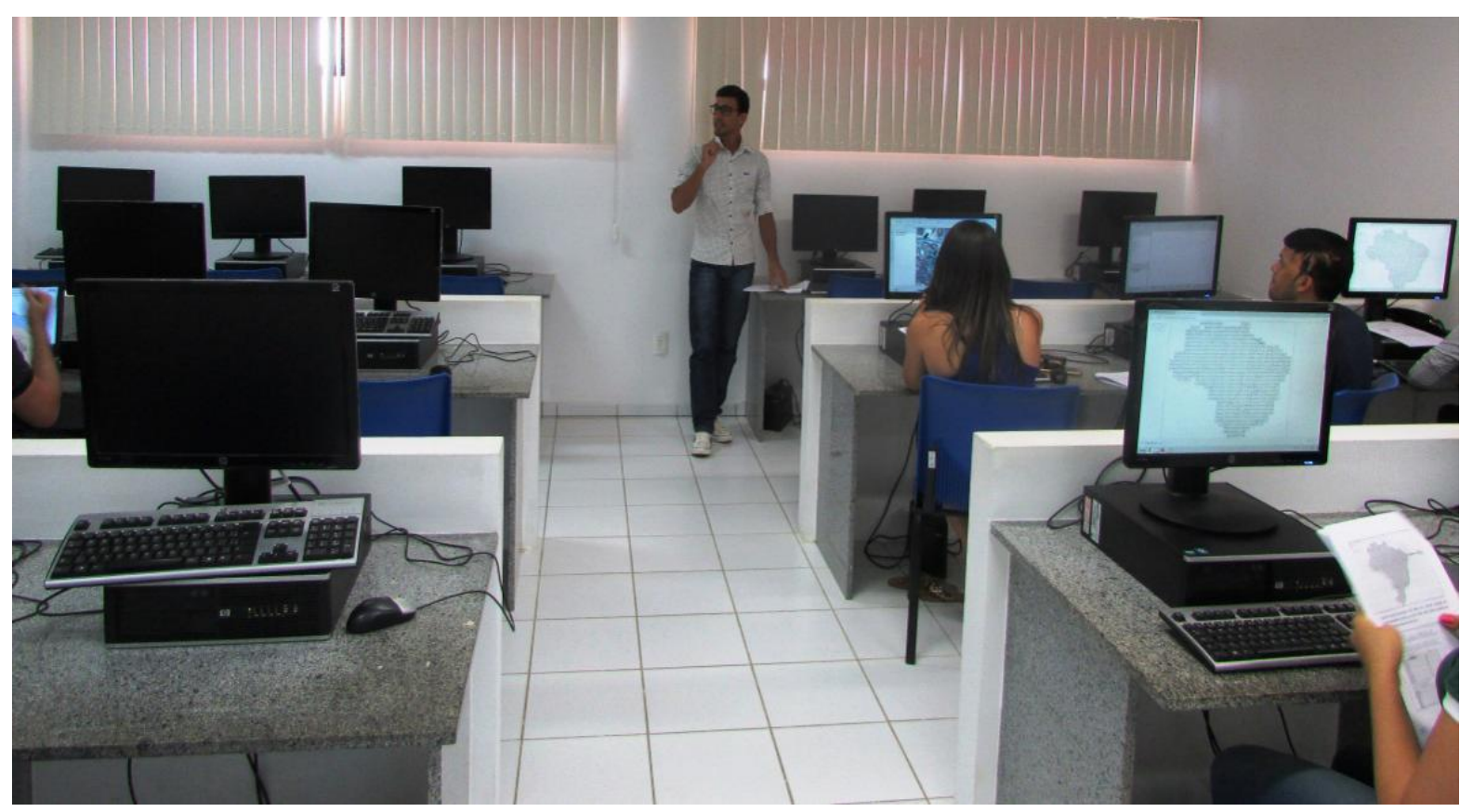

Figura 01. Aplicação do Minicurso. Fonte: Arquivo pessoal 
Por fim, foi aplicado um questionário com todos os participantes do curso, a fim de que apresentassem algumas informações a respeito da relação deles com o geoprocessamento, sobre a aplicação do minicurso e sugestões para possíveis novos cursos.

\subsection{Análise dos dados}

Sobre os dados coletados a partir do questionário, foi possível perceber que, do universo total de participantes, $66,66 \%$ possuíam conhecimentos regulares sobre o uso de SIG; $22,22 \%$ possuíam um bom conhecimento; e apenas $11,11 \%$ tinham um conhecimento ruim, como mostra o Gráfico 1.

Assim, pode-se presumir que os participantes necessitam de atividades práticas regulares para que possam atualizar seus conhecimentos, pois pressupõe-se que a maioria possui um conhecimento regular acerca da prática em geoprocessamento.

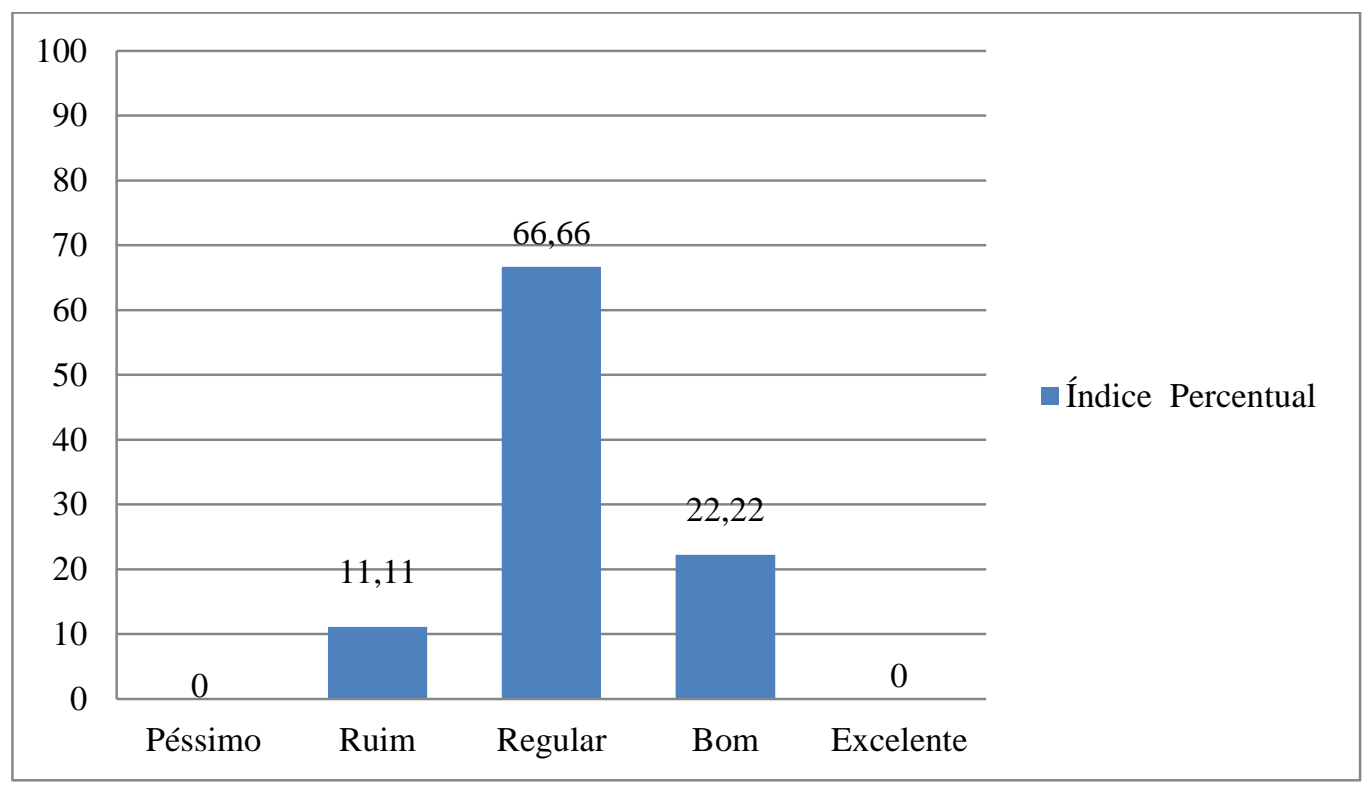

Figura 02. Gráfico com os dados dos conhecimentos prévios dos participantes em relação aos Sistemas de Informação Geográficas (em \%). Fonte: Dados da entrevista. 
Quando foi solicitado para os participantes julgarem a importância do uso dessas tecnologias para o desenvolvimento de aulas no ensino de Geografia, 88,88\% responderam ser essencial, e apenas 11,11\% atribuíram uma importância no nível "bom” (Gráfico 2). Dessa forma, entende-se que a maioria dos participantes se inscreveram no curso, tendo em mente a importância dessa ferramenta como recurso didático para a o Ensino de Geografia.

A ausência das respostas: "sem nenhuma importância" ou "indiferente" demonstra algo certamente óbvio, pois nenhum participante frequentaria o curso se não houvesse a ideia de importância no aprendizado da técnica. Porém, a diferença entre as respostas: "bom" e "essencial", demonstra que, a parcela que atribuiu o nível "bom", talvez tenha respondido dessa forma, não por dar menos importância ao curso, mas por compreender que o uso de geotecnologias no Ensino de Geografia é algo complementar ou, talvez, facultativo, enquanto que a grande parcela acreditou ser algo totalmente ou quase indispensável.

Por fim, outro interesse na sondagem realizada por esta pergunta, pretendeu medir o nível de interesse dos participantes no uso da técnica, sendo parâmetro para a realização de minicursos futuros, trazendo aplicações mais avançadas.

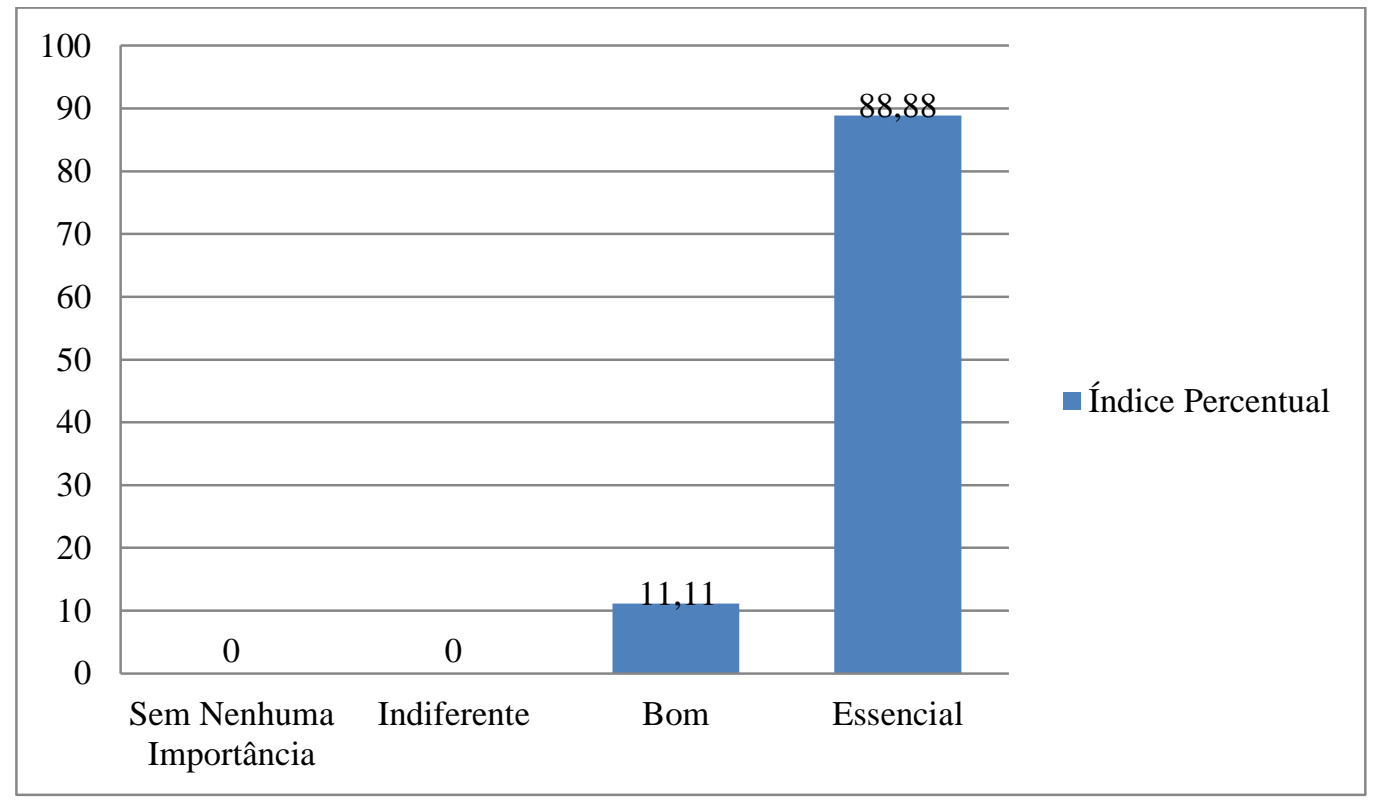

Figura 03. Gráfico com os dados do julgamento do uso dessas tecnologias para o desenvolvimento das aulas de geografia (em \%). Fonte: Dados da entrevista. 
O gráfico abaixo (Gráfico 3), apresenta sugestões dos participantes para periodizar o minicurso, demonstrando que 55,55\% almejam que o mesmo ou até outros cursos de natureza semelhante sejam realizados trimestralmente; $44,44 \%$, preferiram semestralmente; e ninguém optou pelo período anual. Logo, percebe-se que o interesse em continuar praticando o uso desta ferramenta existe, demonstrando a importância de realização de cursos desta natureza, e que essa prática deve tentar ser atendida, tendo em vista que, quando atuantes, os participantes terão mais a oferecer para seus alunos, além de atuarem como multiplicadores deste conhecimento.

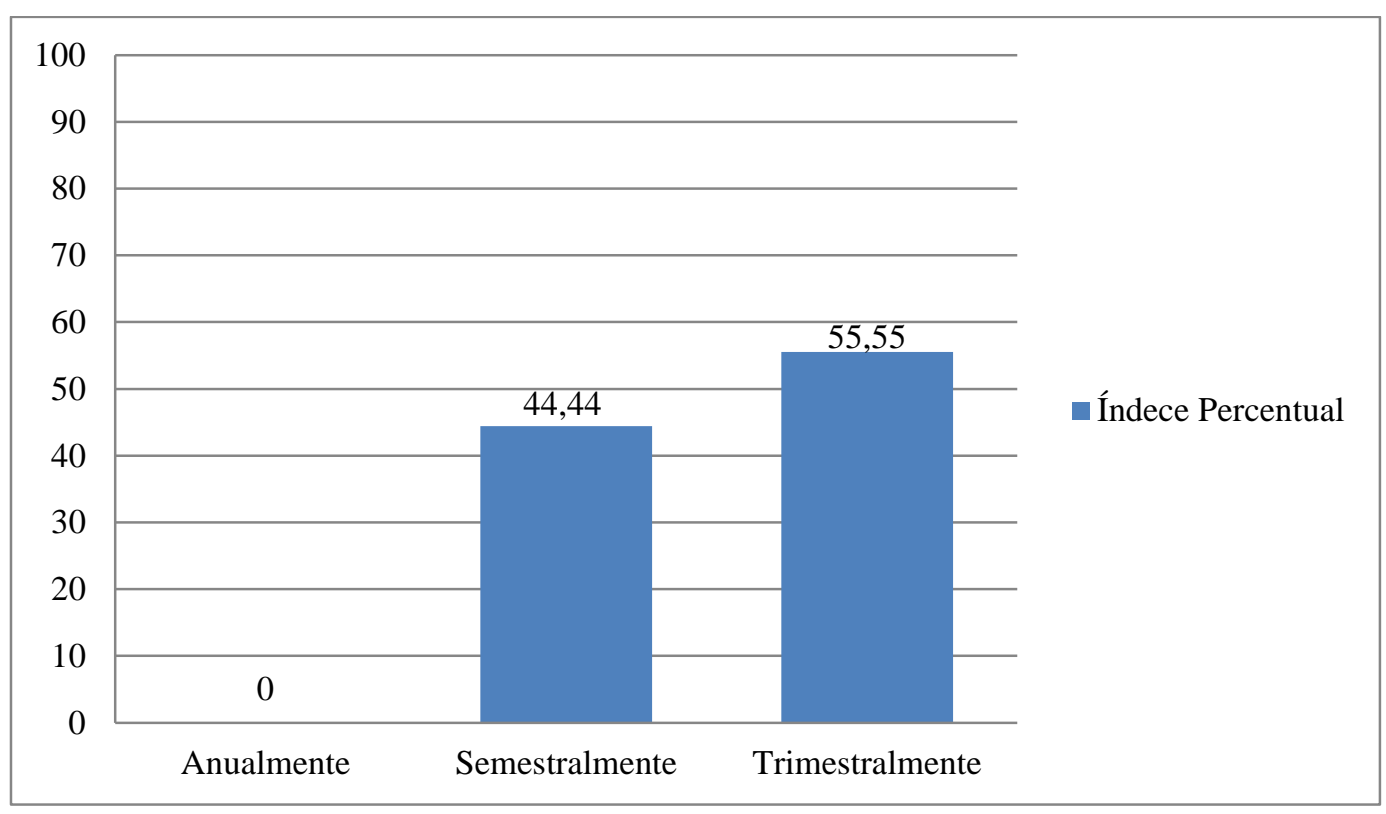

Figura 04. Gráfico com os dados da periodização para realização deste minicurso (em \%). Fonte: Dados da entrevista.

Como a maioria deu significância à importância do minicurso, foi solicitado aos participantes que atribuíssem uma nota, representando a contribuição do minicurso para a formação profissional dos mesmos. O resultado, demonstrado no gráfico 4, mostra que mais da metade avaliou o minicurso de forma positiva, havendo apenas um que atribuiu a nota mínima. 


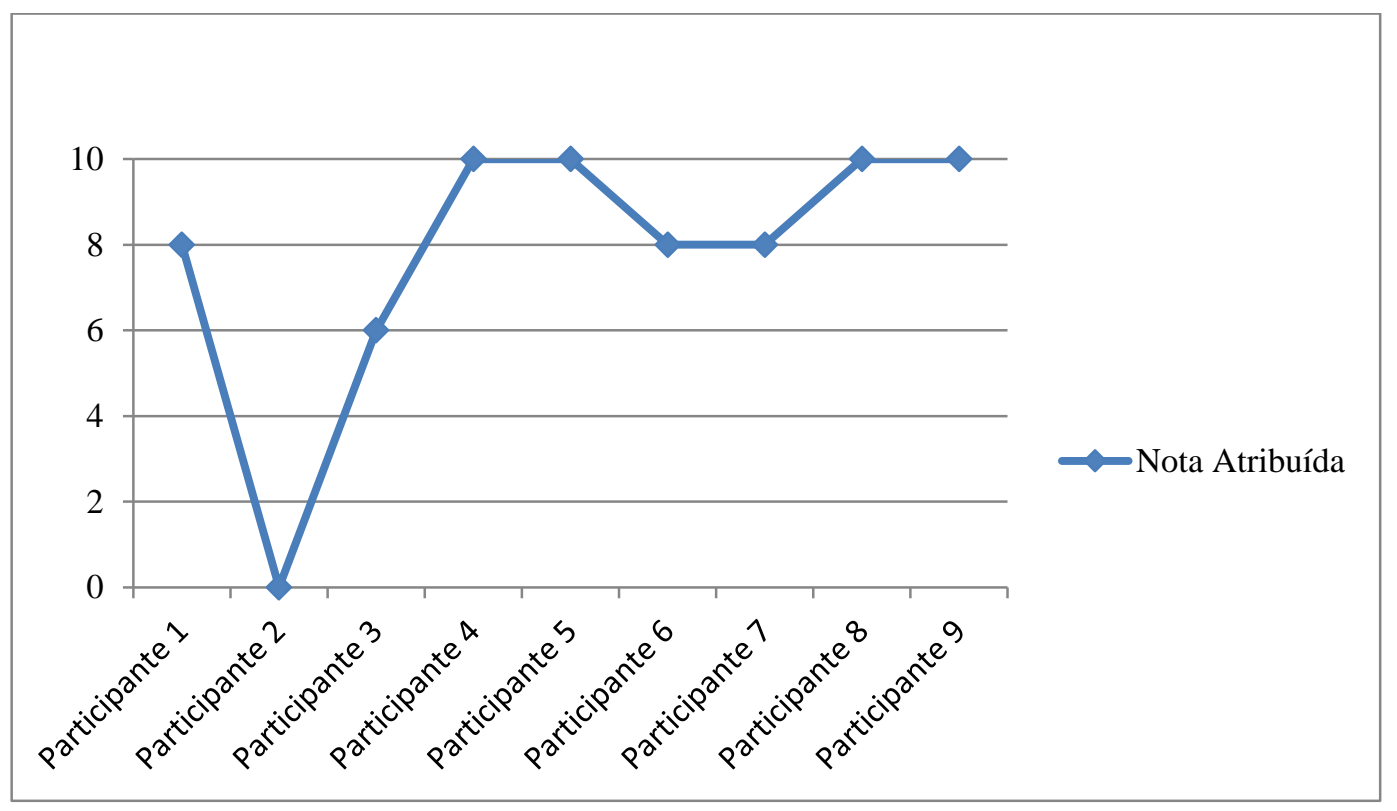

Figura 05. Gráfico com os dados da contribuição do minicurso para desenvolvimento profissional segundo os participantes. Fonte: Dados da entrevista.

Mesmo a maioria dos alunos tendo uma relação regular com os Sistemas de Informações, não impediu o desenvolvimento do minicurso. Segundo suas respostas no questionário, os mesmos se interessaram pelo minicurso por julgarem essencial para o desenvolvimento das aulas de Geografia, por isso consideraram de máxima importância e possuir contribuição essencial para a formação docente.

\section{CONSIDERAÇÕES FINAIS}

A realização desse projeto trouxe gratificações generalizadas e indagações sobre o futuro dos docentes da Geografia. Foi perceptível o grau de importância da experiência de ministrar um minicurso para professores e futuros professores, percebendo o avanço dos mesmos no uso de uma ferramenta que pode vir a ser considerada nova para o Ensino de Geografia. Dessa forma, fica claro que, para os participantes que, no caso dos participantes que estão quase concluindo a Licenciatura em Geografia, por exemplo, existe a consciência acerca da importância das geotecnologias como ferramenta do ensino, e que, por isso, têm o interesse de aprender e praticar mais vezes. Esta perspectiva, abre espaço para um futuro quadro de professores de Geografia mais habituados ao avanço tecnológico, sendo capazes de 
utilizar essas ferramentas para potencializar sua atuação docente, contribuindo para o desenvolvimento de novas formas de ensinar Geografia.

Sobre as indagações, pode-se questionar o motivo de não ter havido este interesse quando cursaram esta disciplina. Seria por a disciplina não estar voltada ao ensino de geografia, mas sim a pesquisa geográfica? Seria falta de maturidade intelectual ou de interesse por parte dos graduandos? Essas são perguntas que podem vir a ser feitas a professores recém-formados.

Das dificuldades, entendeu-se que o período de realização implicou diretamente na abrangência do minicurso, pois a data divergia com o final do período letivo da faculdade e do ensino da rede pública da cidade de Caicó/ RN.

Porém, mediante todos os erros e acertos, pretende-se estender esta iniciativa para a realização de outras oficinas, não apenas utilizando método e técnicas ligadas às Geotecnologias, mas, também, à construção de modelos tridimensionais, tanto em ambiente virtual quanto a partir de técnicas da Cartografia Tradicional, além de iniciativas voltadas à educação ambiental em nível de vulnerabilidade socioambiental, visando despertar a comunidade local acerca da importância de preservar o ambiente, de modo que este foi apenas um primeiro passo.

\section{REFERÊNCIAS}

AGUIAR, Ponciana Freire de. Geotecnologias como Metodologias Aplicadas ao Ensino de Geografia: Uma Tentativa de Integração. Geosaberes. Fortaleza, v. 4, n. 8, p. 54-66, jul./ dez. 2013. ISSN: 2178-0463. Disponível em: <http://www.geosaberes.ufc.br/seer/index.php/geosaberes/article/view/184/182>. Acessado em: 29 jun. 2017.

ARELARO, Lisete Regina Gomes. Resistência e Submissão: a reforma educacional na década de 1990. In: KRAWCZYK, Nora; CAMPOS, Maria Malta; HADDAD, Sérgio. (Orgs.). O Cenário Educacional Latino-americano no Limiar do Século XXI: Reformas em Debate. - Campinas, SP: Autores Associados, 2000.

BRASIL. Parâmetros Curriculares Nacionais: história e geografia. Ministério da Educação. Secretaria da Educação Fundamental. - $3^{a}$ ed. - Brasília: A Secretaria; Ministério da Educação, 2001. v. 5. p. 125-159. 
CASTELLAR, Sônia; VILHENA, Jerusa. O uso de Diferentes Linguagens em Sala de Aula. In: ENSINO DE GEOGRAFIA. $1^{a}$ reimpressão., 1. ed. - São Paulo: Cengage Learning, 2011.

CAVALCANTI, Lana de Souza. Geografia, escola e construção de conhecimentos. Campinas, SP: Papirus, 1998. - (Coleção Magistério: Formação e Trabalho Pedagógico).

DUARTE, Paulo Araújo. Fundamentos de Cartografia. 3. ed. Florianopolis: ed. da UFSC, 2008.

FITZ, Paulo Roberto. Geoprocessamento sem complicação. -- São Paulo: Oficina de Textos, 2008.

NEVES, Ronaldo José; CRUZ, Carla Bernadete Madureira. O uso de representações gráficas geradas a partir de ferramentas de geoprocessamento nos estudos em sala de aula - Pananal de Cáceres, MT. In: $1^{\circ}$ SIMPÓSIO DE GEOTECNOLOGIAS NO PANTANAL (GEOPANTANAL), 2006, Campo Grande,MS, Brasil. Anais... Embrapa Informática Agropecuária/ INEP, 2006. Artigos, p. 482-491.

PONTUSCHKA, Nídia Nacib; PAGANELLI, Tomoko Iyda; CACETE, Núria Hanglei. Para Ensinar e Aprender Geografia. - 3 ${ }^{\text {a }}$ ed. - São Paulo: Cortez, 2009.

SIMIELLI, Maria Elena. O MAPA COMO MEIO DE COMUNICAÇÃO E A ALFABETIZAÇÃO CARTOGRÁFICA. In. Cartografia Escolar. ALMEIDA, Rosângela Doin de. - 2. ed., $2^{\mathrm{a}}$ reimpressão. - São Paulo: Contexto, 2011.

Recebido em: 11/06/2018

Aceito para publicação em: 29/07/2018 